\title{
USE OF THE EZ-BLOCKER THROUGH THE I-GEL AIRWAY DEVICE FOR VIDEO-THORACIC SYMPATHECTOMY
}

\author{
Arevalo, Julian M.D, Ph.D., Pagazaurtundua, Alejandra M.D., Alvarez, Rafael M.D, Ph.D. ,Arcas, Jose Juan M.D. \\ University Hospital Fundacion Jimenez Diaz, Dept of Anaesthesiology, Madrid, Spain
}

- Background: Video-assisted thoracic (VAT) sympathectomy is used for patients with hyperhidrosis refractory to medical treatment ${ }^{\prime}$. Bronchial blockers (BB) are one of the main choices for achieving one lung ventilation (OLV).

\section{- Case report:}

- A 43 years old female with severe axillary-palmar hyperhidrosis was scheduled for VAT sympathectomy. She asked not to be intubated because she worked as a radio-tv host and was afraid of suffering laryngeal injury.

- I-gel mask and the EZ BB were used in order to avoid intubation.

- The EZ BB was inserted through the l-gel with the aid of a $6.5 \mathrm{~mm}$ endotracheal tube (ETT).

- The bevel of the ETT was left just above the vocal cords and the EZ BB was passed through them under fiberoptic view.

- The ETT was removed and the blocker was properly placed over the carina.

- Peak pressures did not exceed $25 \mathrm{cmH} 2 \mathrm{O}$ during surgery, no air leakages were observed and the patient did not suffer any airway injury
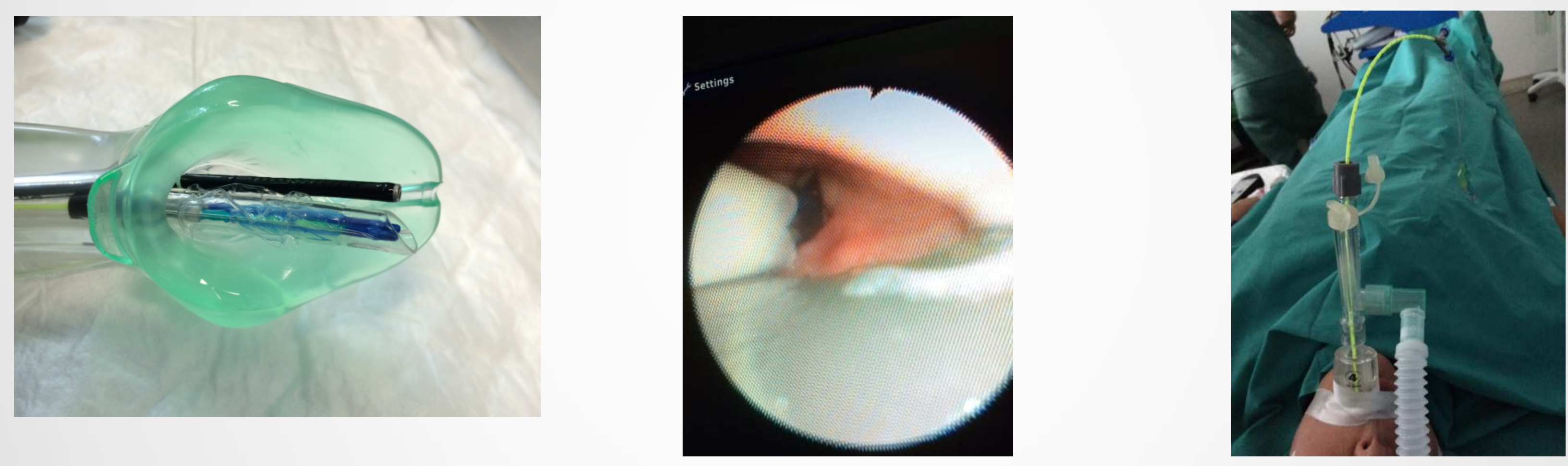

\section{Discussion:}

- Laryngeal morbidity has been more frequently related to endotracheal intubation than supraglottic devices'.

- Direct laryngoscopy, can also damage the airway.

- Postoperative hoarseness, sore throat and vocal cords lesions occur more frequently with DLT than with $\mathrm{BB}^{2}$.

\section{- Learning points:}

- Video-thoracic sympathectomy may be performed with the l-gel and the EZ BB, which is a technique that has not been reported so far.

- Patients who are afraid of suffering laryngeal damage secondary to endotracheal intubation may benefit from the use of supraglottic devices and BB instead of double lumen tubes, depending on the surgery and the clinical situation.

\section{- References:}

I.Saeki $\mathrm{H}$, et al. [Postoperative sore throat and intracuff pressure: comparison among endotracheal intubation, laryngeal mask airway and cuffed oropharyngeal airway]. Masui. 1999 Dec;48(12):1328-31.

2.Knoll H, et al.Airway injuries after one-lung ventilation: a comparison between double-lumen tube and endobronchial blocker: a randomized, prospective, controlled trial. Anesthesiology. 2006 Sep; 105(3):47I-7. 